\title{
SOCIO-CULTURAL AND HEALTH TECHNICAL FACTORS AFFECTING REFERRAL SYSTEM IN EAST FLORES, EAST NUSA TENGGARA
}

\author{
Rafael Paun \\ School of Health Polytechnic, Kupang
}

\begin{abstract}
BACKGROUND: An effective referral system ensures a close relationship between all levels of the health technical and helps to ensure people receive the best possible care closest to home. A good referral system can help to ensure: (1) Clients receive optimal care at the appropriate level and not unnecessarily costly; (2) Hospital facilities are used optimally and costeffectively; (3) Clients who most need specialist service can accessing them in a timely way; (4) Primary health services are well utilized and their reputation is enhanced. This study aimed to determine socio-cultural and health technical factors affecting referral system in East Flores, East Nusa Tenggara.
\end{abstract}

SUBJECT AND METHODS: This was a cross sectional study conducted in East Flores, East Nusa Tenggara. A sample of 22 community health center, district hospital, and district health office in East Flores, East Nusa Tenggara, was selected for this study. The dependent variable was referral system. The independent variables were socio-cultural and health technical factors. Base on factor analysis, the socio-cultural factors consisted of several important indicators: (1) Referral pattern; (2) Referral culture; (3) Geographical condition; (4) Transportation; and (5) Cost. The health technical factors consisted of several important indicators: (1) Referral criteria; (2) Referral capacity; and (3) Referral model. The data were collected by a questionnaire, interview, and document review. The data was analyzed by a multiple linier regression.

RESULTS: Both socio-cultural factors $(b=0.95 ; p=0.041)$ and health technical factors $(b=0.99 ; p=0.037)$ had positive relationship with referral system.

CONCLUSION: Both socio-cultural factors and health technical factors are important determinants for referral system. If referral system is to be improved, then several indicators that shape both socio-cultural factors and health technical factors must be enhanced.

Keywords: referral system, socio-cultural factors, health technical factors 